\title{
Pengaruh Kompetensi, Motivasi, dan Lingkungan Kerja terhadap Kinerja Dosen Perguruan Tinggi Swasta Daerah Istimewa Yogyakarta
}

\author{
Huda Khoyrun $^{1)}$, Aftoni Sutanto ${ }^{2)}$, Abdul Choliq Hidayat ${ }^{3)}$ \\ 1), 2), 3) Program Studi Magister Manajemen, Universitas Ahmad Dahlan Yogyakarta \\ Jl. Pramuka No.42, Pandeyan, Kec. Umbulharjo Yogyakarta 55161 \\ Email: hudakhoyrun@yahoo.co.id ${ }^{l)}$
}

\begin{abstract}
This study aims to determine the effect of competence, motivation and work environment both partially and jointly on the performance of lecturers of the Yogyakarta Private University. This research is a quantitative research. Data collection using a questionnaire method (questionnaire) that has been tested for validity and reliability, while data analysis is done using multiple linear regression analysis. This research stamp was a lecturer in the Private University of Yogyakarta with a sample collection technique using convenience sampling. The results showed that: 1) Competence has a significant effect on the performance of lecturers, this is indicated from the results of the t-test of 11,687 with a significance of 0,000. 2) Motivation has a significant effect on the performance of lecturers, this is indicated from the results of t count of 4.330 with a significance of 0,000. 3) The Work Environment does not affect lecturer performance. 4) Competence, Motivation and Work Environment together have a significant effect on the performance of lecturers, this is indicated by an $F$ count of 64,466 with a significance of 0,000. With a large effect of 77.5\%, while the remaining $22.5 \%$ is influenced by other independent variables that are not thorough.
\end{abstract}

Keywords: Competence, Motivation, Work Environment, Performance

ABSTRAK

Penelitian ini bertujuan untuk mengetahui pengaruh kompetensi, motivasi dan lingkungan kerja baik secara parsial maupun secara bersama-sama terhadap kinerja dosen Perguruan Tinggi Swasta Daerah Istimewa Yogyakarta. Penelitian ini merupakan penelitian kuantitatif. Pengumpulan data menggunakan metode angket (kuesioner) yang telah diuji validitas dan reliabilitasnya, sedangkan analisis data dilakukan dengan menggunakan analisis regresi linier berganda. Sempel penelitian ini adalah dosen Perguruan Tinggi Swasta Daerah Istimewa Yogyakarta dengan teknik pengumpulan sampel menggunakan convinience sampling. Hasil penelitian menunjukan bahwa: 1) Kompetensi berpengaruh signifikan terhadap kinerja dosen, hal ini ditunjukan dari hasil uji t hitung sebesar 11,687 dengan signifikansi 0,000. 2) Motivasi berpengaruh signifikan terhadap kinerja dosen, hal ini ditunjukan dari hasil t hitung sebesar 4,330 dengan signifikansi 0,000. 3) Lingkungan Kerja tidak berpengaruh terhadap kinerja dosen. 4) Kompetensi, Motivasi dan Lingkungan Kerja secara bersama-sama berpengaruh signifikan terhadap kinerja dosen, hal ini ditunjukan dengan F hitung sebesar 64,466 dengan signifikansi 0,000 . Dengan besar pengaruh sebesar $77,5 \%$, sedangkan sisanya sebesar $22,5 \%$ dipengaruhi oleh variabel bebas lain yang tidak teliti.

Kata Kunci: Kompetensi, Motivasi, Lingkungan Kerja, Kinerja

\section{Pendahuluan}

Pertumbuhan perguruan tinggi di Indonesia saat ini diharapkan dengan tantangan globalisasi pendidikan yang sangat ketet. Globalisasi dunia pendidikan tinggi kini mulai deras merambah Indonesia. Upaya pemerintah dalam meningkatkan mutu pendidikan tinggi Indonesia untuk memajukan bangsa Indonesia yang sangat besar dan berkeadilan. Hasil upaya yang sudah dirintis beberapa waktu yang lalu adalah terbitnya beberapa kebijakan pemerintah yang tertuang dalam surat edaran. Tujuan dalam Surat Edaran Direktorat Jendral Pendidikan Tinggi No 407/D/T/1996 dinyatakan bahwa status akreditasi PT atau Program Studi merupakan cerminan kualitas PT yang mengambarkan mutu, efisiensi, serta relevansi program studi. Kualitas merupakan tangung jawab manajemen dan pimpinan harus menciptakan sistem dan proses yang menghasilkan kualitas.
Kemudian surat edaran Nomor: 302/D/T 2003 tanggal 14 Februari 2003 tentang surat izin penyelenggaraan program studi bagi perguruan tinggi. Surat edaran tersebut memberlakukan izin penyelenggaraan didasarkan atas jenjang program, yaitu jenjang S3, S2, D3, D2 dan D1 selama 3 tahun, dan jenjeng $\mathrm{S} 1$ dan D4 adalah 4 tahun.

Harapan pemerintah mengeluarkan surat edaran di atas adalah agar semua PT di Indonesia umumnya dan perguruan tinggi Provinsi Daerah Istimewa Yogyakarta. Khususnya memiliki kualitas yang lebih baik sehingga dapat mengarahkan produktivits yang lebih tinggi, yang pada gilirannya dapat membangun kekuatan daya saing atau kompetitif jangka panjang. Pencapaian kualitas dan daya saing yang lebih baik diharapkan juga dapat tercermin pada tingkat level akreditasi yang diperoleh setiap perguruan tinggi. 
Namun kenyataanya, berdasarkan data dari BAN PT akhir maret 2015 jumlah program studi di Daerah Istimewa Yogyakarta sebanyak 935 hasilnya belum mengembirakan. Hasil tersebut dapat digambarkan sebagai berikut: program studi yang terakreditasi A sebesar 18,77\%, terakreditasi B sebesar 49,30\%, terakreditasi C sebesar 21,92\%, yang akan kedaluwarsa sebesar $2,13 \%$, kedaluwarsa sebesar $2.56 \%$, re-akreditasi sebesar 2,99\%. Selain itu, Susanto (2014) menjelaskan hasil analisis penelitiannya bahwa pada tahun 2000 jumlah PTS yang tercatat di Kopertis Wilayah V Daerah Istimewa Yogyakarta sebanyak 134, kemudian pada tahun 2009 berkurang menjadi 124 PTS. Fenomena masih banyaknya program studi berakreditasi $\mathrm{C}$ dan status akreditasi sudah kedaluwarsa pada beberapa program studi menggambarkan bahwa kinerja program studi masih rendah. Kenyataan tersebut tidak sesuai dengan harapan pemerintah, yang telah mengeluarkan surat edaran untuk mendorong adanya peningkatan kinerjanya yang dicerminkan dengan perolehan akreditasi institusi maupun akreditasi program studi yang baik.

\section{Landasan Teori}

Rendahnya kinerja perguruan tinggi ini ditengarai antara lain karena kurangnya sumber daya dan fasilitas, program studi yang masih baru, desain kurikulum lemah, bangunan gedung tidak memenuhi syarat, lingkungan kerja buruk, system dan prosedur tidak sesuai, jadwal kerja yang tidak terencana, pengembangan staf yang tidak memadai, dan secara umum program studi memiliki manajemen kualitas yang lemah (Gaspersz, 2011).

Upaya yang dilakukan untuk meningkatkan mutu pendidikan program studi belum mencapai hasil yang maksimal. Walaupun gengisisan boring akreditasi yang disampaikan oleh Badan Akreditasi Nasional sangat membantu dalam peningkatan kinerja program studi, tetapi secara nasional hasil peningkatan akreditasi program studi masih dominan yang berakreditasi $\mathrm{C}$ dan bahwa beberapa program studi yang peringkat akreditasinya sudah kedaluwarsa.

Kondisi pendidikan khususnya di perguruan tinggi saat ini menunjukkan permasalahan bangsa yang sangat serius dan sangat mendesak untuk diatasi. Selain kinerja perguruan tinggi yang sangat rendah, persaingan perguruan tinggi semakin ketat dan tuntutan dunia pekerjaan yang semakin berat. Jika kondisi ini tidak segera diatasi, maka setiap perguruan tinggi akan menghadapi tantangan yang sangat berat. Kenyataan ini menjadi tantangan bagi seluruh dosen yang bersangkutan terhadap kinerja program studi melalui peningkatan kualitas manajemen mutu yang diimplementasikan pada setiap level operasi atau proses dari setiap area fungsional organisasi yang menggunakan sumber daya dan modal yang tersedia.

Kinerja dosen memiliki kontribusi dan pengaruh terhadap mutu pendidikan perguruan tinggi dan peningkatan kinerja dosen akan diikuti dengan mutu pendidikan di perguruan tinggi Yusron Razak dkk (2016). Dosen yang bermutu diharapkan dapat meningkatkan kualitas dan kinerja perguruan tinggi sehingga nantinya dapat membuat Perguruan Tinggi Swasta Daerah Istimewa Yogyakarta mampu untuk menghadapi persaingan yang semakin ketat. Allah SWT berfirman dalam surat Al-Ahqaaf, ayat 19 yang berarti Dan bagi masing-masing mereka derajat menurut apa yang telah mereka kerjakan dan agar Allah mencukupkan bagi mereka (balasan) pekerjaan-pekerjaan mereka sedang mereka tiada dirugikan. Dari ayat tersebut bahwasanya Allah pasti akan membalas setiap amal perbuatan manusia berdasarkan apa yang telah mereka kerjakan. Artinya jika seseorang melakukan pekerjaan dengan baik dan dan menunjukan kinerja yang baik pula bagi organisasinya maka akan mendapat hasil yang baik pula dari pekerjaannya. Kinerja dosen perguruan tinggi swasta dipengaruhi oleh banyak faktor, pada penelitian ini peneliti menggunakan variabel Kopetensi, Motivasi dan Lingkungan Kerja sebagai indikator yang harus diperhatikan dalam meningkatkan Kinerja Dosen Perguruan Tinggi Swasta Daerah Istimewa Yogyakarta.

\section{Metode Penelitian}

\subsection{Jenis Penelitian}

Penelitian ini menggunakan pendekatan statistic kuantitatif korelasional, pada penelitian ini peneliti ingin meneliti mengenai hubungan atau korelasi antara beberapa variabel pada data yang akan dikumpulkan dan sekaligus menguji signifikansinya. Peneliti akan menguji 2 variabel yaitu variabel dependen (Kinerja) dan variabel independent (Kompetensi, Motivasi dan Lingkungan Kerja).

\subsection{Waktu Dan Tempat Penelitian}

Penelitian ini dilakukan di Perguruan Tinggi Swasta Daerah Istimewa Yogyakarta. Penelitian ini dilakukan selama 5 bulan dari bulan Juli 2019 sampai bulan November 2019.

\subsection{Populasi Penelitian}

Populasi dari penelitian ini adalah seluruh dosen perguruan tinggi swasta Daerah Istimewa Yogyakarta berjumlah 6.541 dosen PTS yang terdiri dari 18 unversitas, 4 institut, 39 sekolah tinggi, 47 akademik, dan 8 politeknik. Perguruan tinggi yang berbentuk universitas, sekolah tinggi, dan akademi dipilih untuk dijadikan obyek sempel penelitian. Responden pada penelitian ini adalah dosen perguruan tinggi swasta yang dipilih secara acak dari jumlah sampel dengan harapan dapat diperoleh kualitas data penelitian yang baik.

\subsection{Teknik Pengambilan Sempel}

Untuk menentukan sampel yang akan digunakan dalam penelitian, terdapat beberapa teknik sampling yang digunakan. Pada penelitian ini menggunakan kovinien sampling yaitu merupakan pemilihan sampel dari siapa saja yang ada atau dijumpai menurut keinginan peneliti.

\subsection{Jenis Dan Sumber Data}

Jenis data yang digunakan pada penelitian ini menggunakan data kuantitatif, (2013), mendefinisikan 
data kuantitatif adalah data yang berbentuk angka atau data kualitatif yang diangkakan (scoring).

Sumber data yang digunakan adalah data primer. Suliyono (2009), mengungkapkan bahwa data primer adalah data yang dikumpulkan sendiri oleh peneliti langsung dari sumber pertama.

\subsection{Teknik Pengumpulan Data}

Pada penelitian ini data diperoleh dengan menggunakan Google Form. Google Form adalah alat yang berguna untuk mambantu merencanakan acara, mengirim survei, mengumpulkan siswa, orang lain kuis dan mengumpulkan informasi yang mudah dengan cara yang efisien, dikutip dari (https://idcould host.com/mengenal-google-form-untuk-kebutuhansurvey-anda/).

\subsection{Teknik Analisis}

Penelitian ini menggunakan regresi linier berganda. Menurut Sujarweni (2007), untuk mengetahui besarnya pengaruh perubahan dari satu variabel terhadap variabel lainnya, yaitu variabel kompetensi (X1), motivasi (X2), dan lingkungan kerja (X3), terhadap kinerja dosen (Y). Metode ini untuk mengetahui pengaruh variabel independent terhadap variabel dependen.

Koefisien determinasi digunakan untuk mengetahui seberapa besar variabilitas variabel-variabel independen mampu memperjelas variabilitas variabel dependen. Koefisien determinasi pada regresi logistik dapat dilihat pada nilai nagelkerke $\mathrm{R}$ Square. Nilai nagelkerke $\mathrm{R}$ Square dapat dienterpretasikan seperti nilai R Square pada regresi berganda, Ghozali (2006).

\section{Pembahasan}

\subsection{Hasil Analisis}

Penelitian ini dilakukan di seluruh Perguruan Tinggi Swasta Di Yogyakarta. Peneliti menyebar kuesioner dengan menggunakan Google Form, guna penyebaran kuesioner untuk melakukan penelitian tersebut. Penyebaran kuesioner dilakukan secara acak pada Grup WhatsApp Perguruan Tinggi Swasta Daerah Istimewa Yogyakarta. Butuh waktu selama 3 hari untuk menyebarkan kuesioner, sedangkan pengembalian dari seluruh responden memerlukan waktu selama 10 Hari.

Dari penyebaran data kuesioner selama 10 hari, dapat ditunjukan hasil perolehan data seperti pada tabel 1 .

Sesuai dengan permasalahan yang telah dikemukanan, maka teknik analisis data yang digunakan dalam penelitian ini meliputi analisis analisis kuantitatif. Teknik perhitungan yang digunakan dalam penelitian ini adalah analisis linier berganda. Sebelum data dianalisis lebih lanjut, maka terlebih dahulu data yang diperoleh tersebut dilakukan uji validitas dan uji reliabilitas sehingga hasil kesimpulan yang diperoleh dalam penelitian ini dapat dinyatakan valid dan tidak menimbulkan nilai yang bias.
Tabel 1. Data Responden

\begin{tabular}{|c|l|c|}
\hline \multicolumn{3}{|c|}{ Data Responden } \\
\hline No. & \multicolumn{1}{|c|}{ Nama Universitas } & Angka \\
\hline 1 & Universitas Ahmad Dahlan & 16 \\
\hline 2 & Universitas Bina Sarana Informatika & 5 \\
\hline 3 & Sekolah Tinggi Pariwisata AMPTA & 6 \\
\hline 4 & Universitas Cokroaminoto Yogyakarta & 6 \\
\hline 5 & STIE Nusa Megarkencana & 3 \\
\hline 6 & Universitas Islam Indonesia & 5 \\
\hline 7 & Universitas Widya Mataram & 2 \\
\hline 8 & STIE Mitra Indonesia & 3 \\
\hline 9 & Institut Sains \& Teknologi AKPRIND & 3 \\
\hline 10 & STIE Solusi Bisnis Indonesia Yogyakarta & 2 \\
\hline 11 & Sekolah Tinggi Teknologi Kedirgantaraan & 3 \\
\hline 12 & Universitas Teknologi Yogyakarta & 3 \\
\hline 13 & Universitas Muhammadiyah Yogyakarta & 3 \\
\hline \multicolumn{2}{|l|}{ Total } & 60 \\
\hline
\end{tabular}

\section{Uji Reliabilitas}

Dalam pengujian ini dilakukan dengan uji statistik Cronbach Alpha $(\alpha)$. Suatu konstruk atau variabel dikatakan reliabel jika memberikan nilai Cronbach Alpha $(\alpha)>0,60$ Adhilla, Fitroh (2013). Hasil uji reliabilitas item pernyataan tentang variabel Kompetensi, Motivasi, Lingkungan Kerja, dan Kinseja Dosen diringkas sebagaimana yang ditampilkan ditabel berikut ini:

Tabel 2. Uji Reliabilitas

\begin{tabular}{|c|c|c|c|}
\hline Variabel & $\begin{array}{c}\text { Cronbach } \\
\text { Alpha ( } \boldsymbol{\alpha})\end{array}$ & $\begin{array}{c}\text { Alpha (Rule of } \\
\text { Thumb) }\end{array}$ & Keputusan \\
\hline Kompetensi & .734 & 0,60 & Reliabel \\
\hline Motivasi & .887 & 0,60 & Reliabel \\
\hline Lingkungan Kerja & .817 & 0,60 & Reliabel \\
\hline Kinerja & .724 & 0,60 & Reliabel \\
\hline
\end{tabular}

Berdasarkan ringkasan hasil uji reliabilitas diatas, maka dapat diketahui nilai koefisien Cronbach Alpha $(\alpha)$ pada masing-masing variabel $>0,60$ sehingga dapat disimpulkan bahwa semua pernyataan dalam penelitian ini adalah reliabel dan dapat digunakan untuk penelitian selanjutnya.

\section{Analisis Regrersi Linier Berganda}

Analisis regresi berganda dilakukan untuk menganalisis seberapa besar pengaruh antara variabel kompetensi, motivasi, dan lingkungan kerja terhadap kinerja dosen Perguruan Tinggi Swasta Di Yogyakarta.

Tabel 3. Analisis Linier Berganda

\begin{tabular}{|c|c|c|c|c|}
\hline Variabel & Koefisien & t Test & Sign & Keterangan \\
\hline Konstanta & .351 & 1.045 & 300 & \\
\hline Kompetensi & .716 & 11.687 & .000 & Signifikan \\
\hline Motivasi & .255 & 4.330 & .000 & Signifikan \\
\hline Lingkungan Kerja & -.018 & -.273 & .786 & Tidak Signifikan \\
\hline F Test & 64.466 & 000 & & \\
\hline R Square & 0,775 & & & \\
\hline
\end{tabular}


Untuk menjawab hipotesis yang pertama yaitu apakah terdapat pengaruh kompetensi terhadap kinerja dosen. Pengujian hipotesis tersebut dilakukan dengan analisis regresi linear dengan uji $\mathrm{t}$ digunakan untuk mengetahui pengaruh variabel bebas yaitu kompetensi terhadap variabel terikat yaitu kinerja Dosen Perguruan Tinggi Swasta Daerah Istimewa Yogyakarta.

\subsection{Diskusi}

Berdasarkan hasil pengujian menunjukkan bahwa Kompetensi (X1) berpengaruh signifikan terhadap Kinerja Dosen Perguruan Tinggi Swasta Daerah Istimewa Yogyakarta. Pada variabel Kompetensi (X1) memiliki koefisien regresi sebesar 0,716 yang berarti jika dosen memiliki pengalaman kerja, Pendidikan, pengetahuan dan keterampilan dalam dirinya sebesar satu satuan maka akan meningkatkan kinerja sebesar 0,716. Hasil penelitian ini sesuai dengan penelitian Muhammad Riyanda (2017), dalam penelitian yang berjudul "Pengaruh Kompetensi Dan Disiplin Kerja Terhadap Kinerja Pegawai Dinas Perizinan Kota Yogyakarta". Hasil penelitian menunjukan bahwa variable kompetensi memiliki pengaruh positif dan signifikan terhadap kinerja pegawai pada Dinas Perizinan Kota Yogyakarta. Kompetensi dari seorang dosen masih harus ditingkatkan terutama mengenai pengalaman kerja yang akan bertambah seiring dengan berjalannya waktu, pendidikan atau pengetahuan dosen akan sangat membantu dosen dalam menjalankan pekerjaannya dengan baik. Dan Keterampilan individu dosen akan sangat penting dalam menjalankan tugasnya.

Berdasarkan hasil pengujian menunjukkan bahwa Motivasi (X2) berpengaruh signifikan terhadap Kinerja Dosen Perguruan Tinggi Swasta Daerah Istimewa Yogyakarta. Pada variabel Motivasi (X2) memiliki nilai koefisien sebesar 0,255 yang berarti jika motivasi naik sebesar satu satuan maka kinerja akan naik sebesar 0,255. Hasil penelitian ini sesuai dengan penelitian Nadia Karina (2017), dalam penelitian yang berjudul "Analisis \{Pengaruh Kompetensi dan Motivasi Terhadap Kinerja Karyawan PT. PLN Persero Kantor Distribusi Wilayah Lampung". Hasil penelitian menunjukan bahwa variable kompetensi dan Motivasi berpengaruh positif signifikan baik secara parsial dan simultan pada Kinerja Karyawan PT. PLN Persero Kantor Distribusi Wilayah Lampung. Motivasi merupakan salah satu factor internal dari individu dosen, maka motivasi tetap harus dijaga agar para dosen tetap memberikan performa atau kinerja yang baik.

Berdasarkan hasil pengujian menunjukkan bahwa Lingkungan Kerja (X3) tidak berpengaruh terhadap Kinerja Dosen Perguruan Tinggi Swasta Daerah Istimewa Yogyakarta. Pada variabel Lingkungan Kerja (X3) memiliki nilai koefisien sebesar -0,018 yang berarti jika variabel Lingkungan Kerja naik satu satuan maka akan menurunkan kinerja dosen sebesar -0,018. Hasil penelitian ini sesuai dengan penelitian Heny Sidanti (2015), dalam penelitian yang berjudul "Pengaruh Lingkungan Kerja, Disiplin Kerja Dan Motivasi Terhadap Kinerja Pegawai Negreri Sipil Di Sekretariat DPRD Kabupaten Madiun". Hasil penelitian menunjukan bahwa variable lingkungan kerja tidak berpengaruh positif signifikan terhadap kinerja Pegawai Negreri Sipil Di Sekretariat DPRD Kabupaten Madiun. Meskipun Lingkungan Kerja tidak berpengaruh tetapi harus tetap diperhatikan dan ditingkatkan dari segala hal terutama dalam peralatan kerja yang belum mendukung sepenuhnya aktivitas dosen, pelayanan kepada dosen seperti sarana ibadah, sarana kesehatan dan hubungan komunikasi antar dosen harus ditingkatkan demi terjalinnya kerjasama yang baik antar dosen. Pelayanan kepada dosen yang diberikan belum memenuhi keinginan dosen sehingga perlu adanya perbaikan dan kondisi kerja pun harus ditingkatkan oleh setiap Perguruan Tinggi Swasta demi menunjang aktivitas kerja para dosen. Lingkungan Kerja yang baik diharapkan mampu meningkatkan kinerja dosen kepada instansi/organisasinya, dengan tingkat kinerja yang semakin baik diharapkan mampu mempercepat dalam pencapaian tujuan organisasi tersebut.

Untuk variabel kompetensi (X1), motivasi (X2) dan lingkungan kerja (X3) secara bersama-sama berpengaruh signifikan terhadap kinerja dosen Perguruan Tinggi Swasta Daerah Istimewa Yogyakarta. Pengaruh yang timbul adalah positif yaitu semakin baik kompetensi, motivasi dan lingkungan kerja akan semakin tinggi pula kinerja Perguruan Tinggi Swasta Di Yogyakarta. Banyak faktor yang mempengaruhi kinerja dosen, namun pada variable penelitian ini yaitu kompetensi, motivasi dan lingkungan kerja secara bersama-sama menyumbang $77,5 \%$ dalam penentuan apakah seorang dosen memiliki kinerja yang tinggi atau rendah terhadap instansi atau organisasinya.

Dari hasil analisis didapat bahwa lingkungan kerja harus diperhatikan serta ditingkatkan oleh Perguruan Tinggi Swasta terutama dalam hal perlengkapan kerja, peralatan kerja, kondisi ruang, pelayanan kepada dosen dan selain itu hubungan personal juga harus di ciptakan sebaik mungkin oleh dosen agar tercipta kinerja yang lebih baik bagi institusi atau organisasi.

\section{Kesimpulan}

Berdasarkan hasil penelitian dan analisis data, maka peneliti mengambil kesimpulan sebagai berikut:

1. Kompetensi berpengaruh signifikan terhadap Kinerja Dosen Perguruan Tinggi Swasta Daerah Istimewa Yogyakarta.

2. Motivasi berpengaruh signifikan terhadap Kinerja Dosen Perguruan Tinggi Swasta Daerah Istimewa Yogyakarta.

3. Lingkungan Kerja tidak berpengaruh terhadap Kinerja Dosen Perguruan Tinggi Swasta Daerah Istimewa Yogyakarta.

4. Kompetensi, Motivasi dan Lingkungan Kerja secara bersama-sama berpengaruh signifikan terhadap Kinerja Dosen Perguruan Tinggi Swasta Daerah Istimewa Yogyakarta.

Kemampuan model variabel independen yaitu Kompetensi, Motivasi dan Lingkungan Kerja dalam menerangkan variasi variabel dependen yaitu Kinerja 
Dosen sebesar 77,5\% sedangkan 22,5\% dijelaskan dan di terangkan oleh variabel bebas lain yang tidak diamati.

\section{Daftar Pustaka}

Adhila Fitroh, Dyah Fitriani, dan Deny Ismanto. 2013. Modul Praktikum Statistik 2. Yogyakarta. Fakultas Ekonomi Universitas Ahmad Dahlan.19-20.

Susanto, Ahmad. 2014. Teori Belajar dan Pembelajaran di Sekolah Dasar. Jakarta: Kencana Prenada Media Group.

Gaspersz, Vincent. 2011. Sistem Manajemen Kinerja Terintegrasi Balanced Scorecard dengan Malcolm Baldrige dan Lean Six Sigma Supply Chain Management. Jakarta: PT Gramedia Pustaka Utama

Ghozali, Imam. 2006. Structural Equation Modeling, Metode Alternatif dengan Partial Least Square. Edisi 2. Semarang: Badan Penerbit Universitas Diponegoro.

Karina, Nadia. 2017. Analisis Pengaruh Kompetensi dan Motivasi Terhadap Kinerja Karyawan PT, PLN Persero Kantor Distributor Wilayah Lampung. Tesis. Lampung, Universitas Lampung.

Riyanda, Muhammad., 2017. Pengaruh Kompetensi Dan Disiplin Kerta Terhadap Kinerja Pegawai Pada Dinas Perizinan Kota Yogyakarta. Skripsi. Yogyakarta: Universitas Negeri Yogyakarta.

Sidanti, Heny. 2015. "Pengaruh Lingkungan Kerja, Disiplin Kerja Dan Motivasi Terhadap Kinerja Pegawai Negreri Sipil Di Sekretariat DPRD Kabupaten Madiun". Jurnal JIBEKA Vol. 9. (hlm.44-53). Madiun. STIE Dharma Iswara Madiun.

Sujarweni. V. Wiratna. 2007. Statistika Untuk Penelitian. Yogyakarta; Graha Ilmu

Yusron Razak, Darwyan Syah dan Abd Aziz. (2016). "Kepemimpinan Kinerja Dosen Dalam Peningkatan Mutu Pendidikan Perguruan Tinggi”. Jurnal Penelitan Manajemen Vol. 1No.2 (hlm.40-41). Jakarta. Universitas Islam Negeri Syarif Hidayatullah.

........ 2016. "Surat Edaran BAN PT" https://lldikti12,ristekdikti.go.id/2016/12/01/suratedaran-ban-pt.html. Diakses pada 12 Juni 2019 pukul 07:29 WIB

........ 2016. "Mengenal Google Form Untuk Kebutuhan Survey Anda", https://idcould host.com/mengenal-google-form-untuk-kebutuhansurvey-anda/, Diakses pada 2019 pukul 08.00 WIB 2019. "Berkas Akreditasi 2015 ke BAN-PT" https://dac.telkomuniversity.ac.id/penyerahanberkas-akreditasi-2015-kenan-pt. Diakses pada 02 Agustus 2019 pukul 19.34 WIB 